\title{
FGFR3 NP_000133.1:p.K650E
}

National Cancer Institute

\section{Source}

National Cancer Institute. FGFR3 NP 000133.1:p.K650E. NCI Thesaurus. Code C142088.

A change in the amino acid residue at position 250 in the fibroblast growth factor receptor 3 protein where lysine has been replaced by glutamic acid. 